\title{
Isolation of chloroplasts from marine microalgae Isochrysis galbana Parke suitable for organelle lipid composition analysis
}

\section{Ye Zhong}

Ningbo University https://orcid.org/0000-0001-6801-030X

Yanrong Li

Ningbo University

Jilin Xu ( $\nabla$ xujilin@nbu.edu.cn )

Key Laboratory of Applied Marine Biotechnology, Ningbo University, Ministry of Education of China https://orcid.org/0000-0002-4496-6937

Jiayi Cao

Ningbo University

Chengxu Zhou

Ningbo University

Xiaojun Yan

Ningbo University

\section{Research}

Keywords: Isochrysis galbana Parke, chloroplasts, isolation, lipid analysis

Posted Date: July 27th, 2020

DOl: https://doi.org/10.21203/rs.3.rs-46030/v1

License: (c) (1) This work is licensed under a Creative Commons Attribution 4.0 International License. Read Full License 


\section{Abstract}

Background: Marine microalgae, Isochrysis galbana Parke, is an important diet microalgal species with high nutritional value. Different from other unicellular microalgae, its cell contains two chloroplasts which are the major sites for lipid synthesis.

Results: Here, we optimized a chloroplast isolation approach suitable for I. galbana Parke, and evaluated the purity and integrity of the isolated chloroplasts by microscopic observations and biochemical assays. The chloroplast lipids were sequenced by ultrahigh-performance liquid chromatography-tandem mass spectrometry (UHPLC-MS/MS). Glycolipids were the main chloroplast lipids, and DGDG, MGDG, and SQDG were the most abundant glyceroglycolipids. DGMG and SQMG were not observed among the chloroplast lipids. In addition, DG was the most abundant neutral lipid. A part of fatty acyl R1/R2 with MGMGs, DGDGs, MGDGs, SQDGs, PEs, and PCs were not found in chloroplasts. The fatty acid proportion of chloroplast lipids were increased, decreased, or remained unchanged compared with the whole-cell.

Conclusions: This newly developed isolation approach was a simple and reliable method to isolate chloroplasts with high integrity and purity. Collectively, our findings show that such an isolation approach may be used in studies on many different aspects of chloroplast biology, and offers a useful reference for isolation of chloroplast from other marine microalgae.

\section{Background}

Chloroplasts are the feature components of the microalgae, macroalgae, and plants. As the sites for photosynthesis, they are important to organismal survival and are responsible for carbohydrate metabolism, amino acid biosynthesis, chlorophyll biosynthesis, and lipid biosynthesis [1]. The structure of the chloroplast can be divided into three sub-compartments, and each performs its own functions. The envelope, a double-membrane system surrounding the organelle, contains enzymes involved in carbon metabolism and oxidative stress response, which are associated with lipid metabolism and communication between plastids [2]. The stroma between the inner envelope and the thylakoid membrane contains soluble proteins involved in the Calvin cycle and protein synthesis [3]. The thylakoid membrane, composed of a number of thylakoids stacked on top of each other to form grana and lamellae, is the site for oxygenic photosynthesis. Therefore, chloroplasts are the main sites of organismal biosynthesis and metabolic pathways and have a substantial control on cell survival.

Chloroplast lipids are indispensable for oxygenic photosynthesis. They are the integral components of photosynthetic protein complexes and constituents of mechanisms to protect the photosynthetic machinery $[4,5]$. Besides, lipids constitute the membranes for compartmentalization of the chloroplast and can contribute to the flexibility of protein complexes and stabilize its bilayers [6]. In general, chloroplast lipids play an important role in photosynthesis, which can modify their energetic metabolism and affect organism life activities. A comprehensive understanding of the chloroplast lipid composition 
facilitates the clarification of lipid metabolic machinery, which plays a fundamental role in rational engineering of oils and fatty acids for fuel, industrial feedstocks, and nutritional improvement.

Until recently, only a limited number of studies have focused on chloroplast lipid composition and metabolism in land plants. Chloroplasts are particularly rich in monogalactosyldiacylglycerol (MGDG), digalactosyldiacylglycerol (DGDG), and sulfoquinovosylmonoacylglycerol (SQDG). In higher plant Arabidopsis, galactolipids are essential to support the growth and photosynthesis [7,8]. MGDG, DGDG, SQDG, and phosphatidylglycerol (PG) constitute the thylakoid membranes, which are the integral ingredients of the photosynthetic complexes $[5,9]$. Phosphatidylcholine (PC), lyso-phosphatidylcholine (lyso-PC), or phosphatidic acid (PA) for chloroplast lipids can be produced in the endoplasmic reticulum (ER) and the chloroplast [10]. In unicellular green alga Chlamydomonas reinhardtii, a model species, the building blocks for triglyceride (TG), and membrane lipids are biosynthesized in the chloroplast. PA and its dephosphorylated product diacylglycerol (DG), are produced in the chloroplast, and they primarily function as precursors for structural lipids of the photosynthetic membrane system [11]. In starved cells, galactolipids are maintained to preserve sufficient chloroplast integrity [12]. In general, neutral lipid metabolism of chloroplast has been extensively studied in $C$. reinhardtii. However, there are no comprehensive studies on the microalgal chloroplast lipid composition.

Marine microalgal biomass plays a critical role in the animal food chain. As a golden-brown flagellate marine microalga, Isochrysis galbana Parke is widely adopted as an aquaculture feed for young fish and in bivalve hatcheries due to its high content of polyunsaturated fatty acids (PUFAs) [13]. Previous investigations have shown that the nutritional value of $I$. galbana to Mollusca larvae is greatly attributed to its unique lipid composition [14-16] and that different cultivation temperatures or times can alter the lipid composition of I. galbana. Therefore, many studies have focused on identifying growth conditions that can promote lipid production $[17,18]$. While the whole-cell lipidomics of $I$. galbana is widely studied, the lipid synthesis and biosynthesis of chloroplast remain largely unknown.

A major deterrent in studying the lipid composition of the chloroplast is the technical challenge associated with the isolation and purification of intact chloroplasts. The currently used techniques employ physical or chemical means to break the cell wall and the plasmalemma [19,20]. The isolation techniques of chloroplast have been confined to several higher plants and a model alga. For Arabidopsis, a method for chloroplast isolation relies on protoplastation [21]. However, this method is time-consuming and expensive. To resolve this problem, a simple and cost-effective approach has been developed to isolate a large number of intact chloroplasts from Arabidopsis seedlings [22,23]. For marine plant Posidonia oceanica, an optimized protocol has been adapted from terrestrial plants and can be used to isolate chloroplasts from as minimal tissue as possible [24]. For $C$. reinhardtii mutant, cells are broken by passing them through a 27 -gauge syringe needle $[15,25]$. However, thus far, no universal method for isolation and purification of the chloroplast is available due to the differences in the number, size, gravity, thylakoid membrane structure, and lipid composition of the chloroplast of different plant cells. Thus, developing a suitable chloroplast isolation protocol that can be applied to different plant species is essential. The marine microalgae I. galbana Parke, in which one cell contains two chloroplasts, is 
different from others [26]. The possibility of obtaining intact chloroplasts, which are active in lipid synthesis, from a no cell wall microalga prompted us to attempt the isolation of chloroplasts from $I$. galbana. There are no established techniques for the isolation of intact chloroplasts from I. galbana, and there are no studies on its chloroplast lipid composition. Therefore, a chloroplast isolation technique for the marine microalgae I. galbana that is suitable for studying the organelle lipid composition is an emerging need.

In the present study, we developed a rapid approach for cellular fractionation of I. galbana, by which intact chloroplasts could be isolated. The chloroplasts purified using this approach were mostly intact and contained only minimal contamination. The isolated chloroplasts and their integrity were analyzed by phase-contrast fluorescence microscopy (Leica) and transmission electron microscopy (TEM), and their purity was analyzed by enzyme-linked immunosorbent assay (ELISA). The lipid composition of the chloroplasts isolated from I. galbana was identified by ultrahigh-performance liquid chromatographytandem mass spectrometry (UHPLC-MS/MS).

\section{Methods}

\section{Microalgal culture and sample collection}

I. galbana Parke was provided by the Marine Biotechnology Laboratory of Ningbo University, China. Seawater ( $\mathrm{pH} 8.2$, salinity $22 \%$ ) was subjected to filtration using $0.45-\mu \mathrm{m}$ cellulose acetate membranes, followed by heat sterilization. The culture medium was supplemented with the following nutrients: 100 $\mathrm{mg} / \mathrm{L} \mathrm{KNO}{ }_{3}, 10 \mathrm{mg} / \mathrm{L} \mathrm{KH}_{2} \mathrm{PO}_{4}, 2.5 \mathrm{mg} / \mathrm{L} \mathrm{MnSO}_{4} \cdot \mathrm{H}_{2} \mathrm{O}, 2.5 \mathrm{mg} / \mathrm{L} \mathrm{FeSO}_{4} \cdot 7 \mathrm{H}_{2} \mathrm{O}, 10 \mathrm{mg} / \mathrm{L} \mathrm{EDTA}-\mathrm{Na}_{2}, 6 \mu \mathrm{g} / \mathrm{L}$ vitamin $B_{1}$, and $0.05 \mu \mathrm{g} / L$ vitamin $B_{12}$. Microalgae were maintained in $5,000 \mathrm{~mL}$ conical flasks at $20 \pm 2$ ${ }^{\circ} \mathrm{C}$, with a light intensity of 4,000 Lux (LED) under a 12:12-h light-dark (L:D) photoperiod. Cells were incubated at $4{ }^{\circ} \mathrm{C}$ overnight to metabolize the pyrenoid and starch granules in the chloroplasts, followed by sample collection at the late stationary phase. The cells were centrifuged at $6,000 \times \mathrm{g}$ for $10 \mathrm{~min}$. A blood counting chamber was used to determine the cell density at each time point. All experiments were performed in triplicates, and the results were expressed as the mean \pm standard deviation.

\section{Isolation and purification of intact chloroplast}

Chloroplasts from I. galbana were isolated and purified at $4{ }^{\circ} \mathrm{C}$ or on ice to protect the integrity of chloroplasts, and the pellet was washed and resuspended gently. First, $100 \mathrm{mg}$ of wet weight microalgae was washed twice with $2 \mathrm{~mL}$ of $50 \mathrm{mM} \mathrm{HEPES}-\mathrm{KOH}(\mathrm{pH} 7.8)$ and centrifuged at $800 \times \mathrm{g}$ for $10 \mathrm{~min}$ to remove salts. The chlorophyll concentration of cells was measured according to the study by Arnon [27]. The key step was to gently separate the cell membrane from the plastids, and to this end, the cells were provided with a hypotonic environment by two steps. First, the cells were resuspended in $2 \mathrm{~mL}$ of solution A (300 mM sucrose, 50 mM HEPES-Tris, 2 mM EDTA-Tris, 1 mM MgCl $2,1 \%$ PMSF as a protease inhibitor, $\mathrm{pH}$ 7.8) and centrifuged. Second, the cells were subjected to a lower osmotic shock by resuspending the cell pellet in $2 \mathrm{~mL}$ of solution $\mathrm{B}$ (100 mM sucrose, $50 \mathrm{mM}$ HEPES-Tris, $2 \mathrm{mM}$ EDTA-Tris, $1 \mathrm{mM} \mathrm{MgCl} 2,1 \%$ 
PMSF, pH 7.8) and allowing to stand on ice for 20 min. Subsequently, the cells were successively homogenized at 2,500 r/min for $10 \mathrm{~s}$ and $6,800 \mathrm{r} / \mathrm{min}$ for $15 \mathrm{~s}$, and this process was repeated 3-4 times, followed by centrifugation at $800 \times \mathrm{g}$ for $10 \mathrm{~min}$. For effective separation, the supernatant was set aside, and solution B was added to the cell pellet and subjected to homogenization for 3-4 turns.

The supernatant was centrifuged at $1,000 \times \mathrm{g}$ for $10 \mathrm{~min}$ to remove nuclei and intact cells, and the crude chloroplasts were collected by centrifugation at $4,500 \times \mathrm{g}$ for $10 \mathrm{~min}$. The crude chloroplast pellet was gently resuspended in $1 \mathrm{~mL}$ of solution C (300 mM D-sorbitol, $50 \mathrm{mM}$ HEPES-Tris, $10 \mathrm{mM}$ EDTA-Tris, 5 $\mathrm{mM} \mathrm{MgCl}_{2}, 1 \% \mathrm{PMSF}, \mathrm{pH}$ 7.8) using a pipette to avoid disrupting the chloroplasts. The resuspended sample was gently loaded onto several Percoll density gradients (top to bottom: $2 \mathrm{~mL} 10 \%$ Percoll, $3 \mathrm{~mL}$ $30 \%$ Percoll, $3 \mathrm{~mL} 50 \%$ Percoll). All gradient media were prepared in solution C. The Percoll gradients were subjected to centrifugation at $8,000 \times \mathrm{g}$ for $30 \mathrm{~min}$. The intact chloroplast constituted a band at the 30$50 \%$ interface and was collected, diluted with three volumes of solution $\mathrm{D}(300 \mathrm{mM}$ D-sorbitol, $50 \mathrm{mM}$ HEPES-Tris, $10 \mathrm{mM}$ EDTA-Tris, $5 \mathrm{mM} \mathrm{MgCl}_{2}, \mathrm{pH} 7.8$ ), centrifuged at 3,500×g for 10 min twice, and the chlorophyll concentration of the chloroplast was determined. Pellets were stored at $-80^{\circ} \mathrm{C}$.

\section{Electron microscopy}

The modified Spurr method [28] was used to prepare the samples for TEM. Briefly, samples were incubated in $2.5 \%$ glutaraldehyde in phosphate buffer $(0.1 \mathrm{M}, \mathrm{pH} 7.8)$ at $4{ }^{\circ} \mathrm{C}$ for $48 \mathrm{~h}$, washed with phosphate buffer, and then post-fixed with $1 \%$ osmium tetroxide $\left(\mathrm{OsO}_{4}\right)$ for an additional $3 \mathrm{~h}$. Subsequently, samples were dehydrated in a graded series of ethanol, followed by acetone. The specimens were incubated in a mixture of acetone and final Spurr resin mixture overnight, followed by incubation at $70{ }^{\circ} \mathrm{C}$ for more than $9 \mathrm{~h}$. The samples were sectioned using a LEICA EM UC7 ultratome, and the sections were stained by uranyl acetate and alkaline lead citrate, followed by observation using a Hitachi TEM (Model H-7650) at an acceleration voltage of $80 \mathrm{kV}$.

\section{ELISA assays}

Proteins were extracted according to a modified method [29]. Briefly, the samples were ground with liquid nitrogen in a pre-cooled mortar and subsequently sonicated in lysis buffer (8 $\mathrm{M}$ urea, $1 \% \mathrm{PMSF}$ ) on ice three times. The remaining debris was removed by centrifugation at $12,000 \times \mathrm{g}$ at $4{ }^{\circ} \mathrm{C}$ for $10 \mathrm{~min}$. The supernatant was collected, diluted with four volumes of cold acetone, and incubated at $-20^{\circ} \mathrm{C}$ for $24 \mathrm{~h}$, followed by centrifugation at $12,000 \times \mathrm{g}$ at $4{ }^{\circ} \mathrm{C}$ for $10 \mathrm{~min}$. Finally, the obtained pellet was dissolved in phosphate buffer saline (PBS).

According to literature, cytoplasm and mitochondria are common contaminants in chloroplast isolation. The purity of isolated chloroplasts was biochemically assessed using ELISAs to estimate the activities of Phosphoenolpyruvate carboxylase (PEPC) and Cytochrome C oxidase (COX) $[24,25,30]$. The chloroplastspecific enzyme, Ribulose bisphosphate carboxylase oxygenase (Rubisco), was used as a positive control. The enzyme activities were estimated using ELISA kits (Meimian Biotechnology, Jiangsu, China), 
according to the manufacturer's instructions, and the color change was measured spectrophotometrically at $450 \mathrm{~nm}$. Each experiment was conducted with three biological replicates.

\section{Total lipid extraction}

The total lipid was obtained from samples using a modified Bligh and Dyer method [31]. Briefly, freezedried samples were extracted with chloroform/methanol/water $(2: 2: 0.8, \mathrm{v} / \mathrm{v} / \mathrm{v})$ and dried under a gentle stream of $\mathrm{N}_{2}$, and the residue was preserved at $-20^{\circ} \mathrm{C}$. The final lipid residue was resuspended in $\mathrm{CH}_{3} \mathrm{OH}$ before further analysis. The above-mentioned procedures were carried out in triplicates. The results were expressed as mean \pm standard deviation.

\section{UHPLC conditions}

A Thermo Fisher U3000 High-Performance LC system (UHPLC) with an ACQUITY UPLC BEH C8 analytical column (i.d. $2.1 \mathrm{~mm} \times 100 \mathrm{~mm}$, particle size $1.7 \mathrm{~m}$, pore size $130 \AA$ ) was used to perform reversed-phase analysis. Mobile phase A consisted of acetonitrile/water (6:4, v/v), mobile phase B consisted of isopropanol/acetonitrile $(9: 1, \mathrm{v} / \mathrm{v})$, and both phases contained $0.1 \%$ formic acid and $10 \mathrm{mM}$ ammonium acetate. The flow rate was set at $0.2 \mathrm{~mL} / \mathrm{min}$. The gradient elution was programmed as follows: 0-15 min, 60-45\% A; 15.0-18.0 min, 45-35\% A; 18.0-26.0 min, 35\% A; 26.0-28.0 min, 35-0\% A; 28.0-30.0 min, 0\% A; 30.0-30.5 min, returning to an initial $60 \% \mathrm{~A} ; 30.5-40 \mathrm{~min}, 60 \% \mathrm{~A}$. The temperature of the sample chamber was maintained at $8{ }^{\circ} \mathrm{C}$, and the column temperature was maintained at $45^{\circ} \mathrm{C}$. Samples were filtered using a 0.22- $\mu \mathrm{m}$ ultrafiltration membrane (Millipore, Bedford, MA, USA) before injection.

\section{Mass spectrometric conditions}

Mass spectrometry was carried out on a Thermo Scientific ${ }^{\mathrm{TM}} \mathrm{Q}$ Exactive hybrid quadrupole-Orbitrap mass spectrometer equipped with a HESI-II probe. The instrument was operated according to a data-dependent LC-MS/MS method in positive mode and negative mode, respectively. Data were obtained in a centroid mode from 200 to $2,000 \mathrm{~m} / \mathrm{z}$ at a resolution of $70 \mathrm{~K}$, and in a high energy collisional dissociation (HCD) MS/MS mode at a resolution of $17.5 \mathrm{~K}$. The automatic gain control (AGC) target was set at $1 \mathrm{e}^{6}$ for MS and $2 \mathrm{e}^{5}$ for $\mathrm{MS}^{2}$. The capillary voltage was maintained at $3.5 \mathrm{kV}$, and the capillary temperature was set at $350^{\circ} \mathrm{C}$. The sheath gas was $45 \mathrm{arb}$, and the aux gas was $10 \mathrm{arb}$. MS ${ }^{2}$ analysis was carried out on the mass spectrometer with different collision energy and ramp of $25,30 \mathrm{~V}$ in a positive ion mode and 20,24 , $28 \mathrm{~V}$ in a negative ion mode based on the type of lipids. The instrument was previously calibrated in positive mode and negative mode, respectively.

\section{Data processing}

The raw data acquired from LC/MS runs were analyzed on the Thermo Xcalibur ${ }^{\mathrm{TM}}$ system. Lipidsearch software version 4.1 (Thermo Scientific ${ }^{T M}$ ) was used to perform peak identification, lipid identification, peak extraction, peak alignment, peak area, and intensity. According to characteristic fragment ions and fragmentation pathways, glycolipids, phospholipids (PLs), betaine lipids, and non-polar lipids could be 
determined [32-39]. Identification of each lipid class and the acyl chains were further confirmed by MS/MS in positive or negative ion mode, as previously described. The semi-quantitative determination of each lipid was based on the lipid standards (Avanti Polar Lipids Inc., Alabaster, AL) area [32,40].

\section{Results}

\section{Chloroplast yield}

The chlorophyll concentration of the whole-cell and chloroplast were determined. The average yield of intact chloroplasts was $10 \pm 1 \%$ based on the chlorophyll recovery (Additional file 1: Table S1).

\section{Chloroplast characterization and integrity}

Chloroplast debris was accumulated at the $10-30 \%$ percoll gradient interface, the intact chloroplasts constituted a band at the $30-50 \%$ interface, and intact cells were found at the bottom of the tube (Fig. 1). The microscopic pictures for each fraction are shown in Fig. 2 and Fig. 3.

Fig. 3a and Fig. 3b show that there were no intact cells in the purified chloroplasts. Under a phasecontrast microscope, the intact chloroplasts were green and surrounded by a bright halo due to the presence of the chloroplast envelope, and had an integrity of $>85 \%$ (Fig. 3d). When observing the intact cells and isolated chloroplasts using fluorescence microscopy, the isolated chloroplasts emitted red light and were smaller than intact cells (Fig. $3 e$ and Fig. 3f). Examination of cell ultrastructure showed that purified chloroplasts retained their shape, and were intact (Fig. $3 g$ and Fig. 3h).

\section{Chloroplast purity}

PEPC and COX activities in the cell homogenates, crude chloroplasts, and purified chloroplasts were determined, and the data is shown in Table 1 . The differential centrifugation could reduce $54 \%$ cytoplasm and $45 \%$ mitochondrial contamination, and a discontinuous density gradient centrifugation could further reduce $41 \%$ cytoplasm and $51 \%$ mitochondrial contamination. This method resulted in only low activities of PEPC and COX, confirming that there was no significant organelle contamination in the isolated chloroplasts.

\section{Lipid composition of the whole-cell and isolated chloroplast}

In the present study, we analyzed the contents of glycolipids, PLs, sphingolipids, betaine lipids, and acylglycerols in the whole-cell and chloroplast of $I$. galbana Parke. Figure 4 lists the relative amounts of lipid classes in total lipid and the relative amounts of major lipid subclasses in total lipid.

Glycolipids were the main lipid components in the chloroplast and accounted for $55.7 \%$ of the total lipid. As the most abundant glyceroglycolipid in the chloroplast, DGDG, MGDG, and SQDG made up approximately $27.0 \%, 18.4 \%$, and $8.2 \%$ of the total lipid, respectively, which were much higher than those in the whole-cell. The fatty acyl R1/R2 were mostly occupied by 16:1/18:4, 16:1/18:3, and 18:4/18:5 in 
DGDGs, 18:4/18:5, 18:4/18:4, 18:4/18:3, and 14:0/18:4 in MGDGs and 18:4/18:3, 16:0/18:3, and 18:1/18:1 in SQDGs (Additional file 2: Table S2). The percentage of trigalactosyldiacylglycerol (TGDG) in the chloroplast was $1.2 \%$, which was nearly the same as that in the whole-cell. Remarkably, monogalactosylmonoglyceride (MGMG) constituted $9.5 \%$ of glycolipids in the whole-cell, while it only accounted for $0.7 \%$ in the chloroplast. Besides, the fatty acid chains of MGMGs with 16:2 were present in the whole-cell but absent in the chloroplast. Compared to the whole-cell, digalactosylmonoglyceride (DGMG) and sulfoquinovosylmonoacylglycerol (SQMG) were nearly undetectable in the chloroplast. Therefore, our data suggested that these two types of lipids were not components of the chloroplast lipids.

Based on our experimental results, the proportion of acylglycerols was second only to glycolipids, which were abundant in both the whole-cell (25.1\%) and the chloroplast (28.9\%) of I. galbana. Microscopic observations confirmed that chloroplast contained lipid droplets (LD), which were conserved neutral lipid storage organelles (Fig. 5). The proportion of DG in total chloroplast lipid was $20.4 \%$, which was more than that in the whole-cell. Meanwhile, the proportions of monoglyceride (MG) and TG in chloroplast were less than those in the whole-cell.

The proportion of PLs in the total lipid of chloroplast was only slightly more than that in the whole-cell. The proportion of PG in PL was greater compared with the other four PLs in the whole-cell and chloroplast, and the second most abundant PL was PC. The chloroplast exhibited a slight increase in PG and a slight decrease in PC compared with the whole-cell. Other PLs in the chloroplast were detected at lower amounts. PA content of the chloroplast was slightly higher than that of the whole-cell, while phosphatidylinositol (PI) and phosphatidylethanolamine (PE) showed the opposite trends compared with PA. PEs containing fatty acyl R1/R2 with 16:0/20:4, 16:0/22:6, 18:1/20:4, 18:0/20:4, and 18:1/22:6 were not found in chloroplast compared with the whole-cell, and PCs with 18:0/20:4 were also not found in the chloroplast.

We also found sphingolipids, which made up $8.3 \%$ in the whole-cell and $10.4 \%$ in the chloroplast. There was a lot of cerebroside and a small amount of ceramide in sphingolipids. The proportion of betaine lipids was low, which was nearly the same between the whole-cell and chloroplast. Moreover, 14:0 lysoDGCC (lyso-diacylglycerylcarboxyhydroxymethylcholine) and 16:0 lyso-DGCC were not found in chloroplast compared with the whole-cell.

For I. galbana Parke, the fatty acid composition of major lipid classes in whole-cell and chloroplast was given in Figure 6. Compared with the whole-cell, in DGs of the chloroplast, the proportion of 18:1 fatty acids was sharply increased, the proportions of $16: 0,16: 2,18: 0,19: 1$, and 20:5 fatty acids were slightly increased, and the proportions of 14:0, 18:4, and 22:6 fatty acids were slightly decreased. The proportions of 16:1, 18:2, and 18:3 fatty acids in DGs remained unchanged (Fig. 6a). Moreover, in TGs of chloroplast, the proportion of 18:1 fatty acid was sharply decreased, the proportions of 16:1, 18:1, and 18:2 fatty acids were slightly decreased, and the proportions of other fatty acids were slightly increased (Fig. 6b). The PC composition was deeply modified in the chloroplast, with a dramatic elevation in 18:1 and 19:1 
fatty acids and a remarkable reduction in 16:0, 18:2, and 20:4 fatty acids (Fig. $6 \mathrm{~g}$ ). In addition, in PGs of the chloroplast, the proportion of 18:1 fatty acid was substantially increased, and the proportions of other fatty acids were slightly reduced (Fig. 6h). In contrast, the proportions of DGDG, MGDG, SQDG, and glycosphingolipid (GerGl) in the chloroplast were essentially similar to those in the whole-cell.

\section{Discussion}

The marine algae of $I$. galbana differ from other marine unicellular microalgae in their lack of the cell wall. Due to this difference in structure, chloroplast isolation techniques need to be specifically adapted for I. galbana, and here, we report a new isolation approach. SDS, frequently presented in isolation buffers to break up the cell wall, was not added to the isolation buffer in this study. Referred to the disruption method for animal cells [41], our improved method used two-step hypotonic buffers, which was better compared with simplex lysis buffers. Buffer A contained $300 \mathrm{mM}$ sucrose, and buffer B contained only $100 \mathrm{mM}$ sucrose. The two-step hypotonic buffers allow the microalgae cells to gradually detach from the plasma membrane, and the amount of buffers added needs to be strictly controlled. However, as the plasma membrane of $I$. galbana was extremely hard, separation could further be achieved by homogenization to save time. Meanwhile, the two-step hypotonic buffers provided conditions for the next homogenization. A rapid isolation method of chloroplast consisting of the twostep hypotonic buffers and homogenization could save time and increase the yield.

In particular, the multiple homogenization steps were a key feature of the isolation procedure and ensured a high yield of intact chloroplasts. During homogenization, quartz sand mixture $(0.1 \mathrm{~mm}$ and $0.4 \mathrm{~mm})$ was added into the tube to break the cells of I. galbana. The homogenization needs to be thorough, and several short-time homogenizations were used until very little sediment was observed after centrifugation at $800 \times \mathrm{g}$ for $10 \mathrm{~min}$. The supernatant was examined using phase-contrast fluorescence microscopy to ensure the absence of intact cells. The speed of homogenization is also vital for intact chloroplast isolation, and we adopted the intermittent low-speed and high-speed method. With this modification, we could not only isolate the intact chloroplasts but could also avoid thylakoid membrane fragmentation that is usually caused by mechanical heat generated during continuous homogenization. Additionally, continuous low-speed homogenization increases the isolation time substantially, which is not conducive to the separation and protection of intact chloroplasts. Therefore, our method of successive low and highspeed homogenization in this experiment mitigates these issues. The homogenization condition presented here are optimal for I. galbana Parke, and we demonstrated that the osmotic shock and homogenization play a fundamental role for effective cell lysis, organelle separation, and the final isolation of intact chloroplasts.

After homogenization, intact chloroplasts were purified from damaged chloroplasts and intact cells by a Percoll density gradient centrifugation, and two-step gradients were employed for most experiments. Before gradients were added, the tube was rinsed with $1 \%$ BSA. Then the gradients were added slowly along the tube wall to form distinct interfaces. The gradient centrifugation step allowed for the purification of intact, photosynthetically active chloroplasts from I. galbana Parke. 
Microscopy and ELISAs were used to estimate the integrity and purity of the isolated chloroplast. ELISAs is a powerful method for measuring the enzymatic activity and is often applied in biochemical assays not only for animal cells but also for plants and algae [42,43]. ELISAs are rapid, sensitive, specific, and precise [44], therefore, we used it to quantify enzymatic activity. To avoid the inactivation of the enzymes, the samples should go through the entire experimental process, and the sampling process should be synchronous. Cell homogenate, rather than cell fractionation, was selected to determine $100 \%$ of individual enzymatic activity. PEPC and COX are enzymes unique to the cytoplasm and mitochondria, respectively, and chloroplasts do not contain these enzymes [25]. Microscopic images and the Rubisco activity data confirmed the integrity of the isolated chloroplast. The results of the PEPC and COX activities in the cell homogenates, crude chloroplasts, and purified chloroplasts ensured the purity of the isolated chloroplast, indicating that they were suitable for chloroplast lipid composition analysis.

To fully understand the chloroplast lipid composition in I. galbana Parke, we chose the late stationary phase of microalgae for analysis because it is the optimal period with the most lipid accumulation [45]. The chloroplast lipid composition of I. galbana Parke was qualitatively similar to that of other photosynthetic plants. The results of the cellular and chloroplast lipid composition in I. galbana Parke indicated that chloroplasts were the major sites for fatty acid synthesis and lipid biosynthesis. The results of glycolipids were consistent with those reported for chloroplast from land plants like Arabidopsis [46,47]. One important exception was that the content of DGDG was higher compared with the MGDG in this alga. This was probably a consequence of different plant species or cultivation conditions as depending on the plant species, changes in growth conditions can affect the amounts of DGDG and MGMG $[12,48]$.

According to previous reports, acylglycerols are present in minor amounts in Vicia faba [49] and in significant amounts in Mimosa [50]. Our results indicate similar acylglycerols levels in I. galbana Parke and Mimosa. In eukaryotes, lipid droplets serve as the primary depot for energy and neutral lipid storage [51,52], and consistent with other literature, we also observed lipid droplets in the chloroplasts of $I$. galbana Parke (Fig. 5) [53,54]. I. galbana chloroplast lipid droplets contained substantial quantities of storage lipids, and DGs were used for the synthesis of glycolipids and PGs.

In plants and algae, galactolipid, sulfolipid, and PGs are synthesized by DAG, which is derived from the eukaryotic pathway or eukaryotic and prokaryotic pathways $[55,56]$. I. galbana chloroplast lipids had high amounts of unsaturated fatty acids, and were mostly occupied with 14:0, 16:1, 18:3, 18:4, and 18:5 in DGDGs, 14:0, 16:1, 18:1, 18:3, 18:4, and 18:5 in MGMGs, and 14:0, 16:0, 18:1, 18:3, and 18:4 in SQDGs. In PGs, $16: 0$ and 18:1 were the main fatty acids. The position of these fatty acids in the glycerol backbone was different. Fatty acyl residues of DGDGs and SQDGs were mainly with 18 carbon atoms at the $s n-2$ position of the glycerol backbone. In I. galbana, DGDG and SQDG were mostly derived from the eukaryotic pathway. The other two photosynthetic membrane lipids, fatty acyl residues with 16 and 18 carbon atoms, were both distributed at the sn-2 position. Thus, in I. galbana Parke, the MGMG and PG were produced by both the prokaryotic and eukaryotic pathways. 


\section{Conclusions}

To our knowledge, this is the first method that enabled the isolation of intact chloroplasts and delivered lipid yield that was sufficient for sub-cellular lipid composition studies in I. galbana Parke. Our study compares the difference between cellular and chloroplast lipid composition of the marine microalgae $I$. galbana, and analyze the fatty acids of chloroplast lipids. Further work should focus on the changes in chloroplast lipids during the entire growth stage.

\section{Abbreviations}

AGC: automatic gain control; BSA: bovine serum albumin; Chlp: chloroplast; COX: Cytochrome C oxidase; DG: diacylglycerol; DGDG: digalactosyldiacylglycerol; DGMG: digalactosylmonoglyceride; ER: endoplasmic reticulum; GerGl: glycosphingolipid; HCD: high energy collisional dissociation; LD: lipid droplet; lyso-DGCC: lyso-diacylglycerylcarboxyhydroxymethylcholine; lyso-PC: lyso-phosphatidylcholine; M: mitochondrion; MG: monoglyceride; MGDG: monogalactosyldiacylglycerol; MGMG: monogalactosylmonoglyceride; $\mathrm{OsO}_{4}$ : osmium tetroxide; PA: phosphatidic acid; PC: phosphatidylcholine; PE: phosphatidylethanolamine; PEPC: Phosphoenolpyruvate carboxylase; PG: phosphatidylglycerol; PI: phosphatidylinositol; PLs: phospholipids; PUFAs: polyunsaturated fatty acids; Py: pyrenoid; Rubisco: Ribulose bisphosphate carboxylase oxygenase; SDS: sodium dodecyl sulfate; SQDG: sulfoquinovosyldiacylglycerols; SQMG: sulfoquinovosylmonoacylglycerol; TEM: transmission electron microscopy; TG: triglyceride; TGDG: trigalactosyldiacylglycerol; UHPLC-MS/MS: ultrahigh-performance liquid chromatography tandem mass spectrometry; WC: whole-cell.

\section{Declarations}

\section{Acknowledgements}

The authors thank Kai Liao, Pingping Zhan, Zhaoshou Ran, Mei Zhang and Peng Shi for assistance in experiments and helpful comments and suggestions on the manuscript.

\section{Authors' contributions}

The project was coordinated by Ye Zhong and Yanrong Li, and Jilin Xu conducted the experiments. Jiaye Cao and Chengxu Zhou contributed to data collection and analysis. Jilin Xu and Xiaojun Yan designed the experiments and reviewed the manuscript. All authors have read and approved the manuscript.

\section{Funding}


This research was supported by Ningbo Science and Technology Research Projects, China (2019B10006), the National Key Research and Development Program of China (2019YFD0900400), Zhejiang Major Science Project, China (2019C02057) and the Earmarked Fund for Modern Agro-industry Technology Research System, China (CARS-49).

\section{Availability of data and materials}

All data supporting the conclusions of this article are included in this article.

\section{Ethics approval and consent to participate}

Not applicable.

\section{Consent for publication}

All authors are consent for publications.

\section{Competing interests}

The authors declare that they have no competing interests.

\section{References}

1. Zakim D, Herman RH. Regulation of fatty acid synthesis. Am J Clin Nutr. 1969;22(2):1091https://doi.org/10.1093/ajcn/22.2.200.

2. Ferro M, Salvi D, Brugiere $S$, et al. Proteomics of the chloroplast envelope membranes from Arabidopsis thaliana. Molecular \& Cellular Proteomics. 2003;2(5):325-3 https://doi.org/10.1074/mcp.M300030-MCP200.

3. Rolland N, Curien G, Finazzi G, et al. The biosynthetic capacities of the plastids and integration between cytoplasmic and chloroplast processes. Annu Rev Genet. 2012;46:2332https://doi.org/10.1146/annurev-genet-110410-132544.

4. Kelly AA, Froehlich JE, Dormann P. Disruption of the two digalactosyldiacylglycerol synthase genes DGD1 and DGD2 in Arabidopsis reveals the existence of an additional enzyme of galactolipid synthesis. Plant Cell. 2003;15(11):2694-2 https://doi.org/10.1105/tpc.016675. 
5. Kobayashi K, Endo K, Wada H. Role of Lipids in Chloroplast Biogenesis. Subcell Biochem. 2016;86:21-49. https://doi.org/10.1007/978-3-319-25979-6_5.

6. LaBrant E, Barnes AC, Roston RL. Lipid transport required to make lipids of photosynthetic membranes. Photosynthesis Research. 2018;138(3):345-3https://doi.org/10.1007/s11120-018-05455.

7. Hölzl, Georg, Dörmann, Peter. Chloroplast Lipids and Their Biosynthesis. Annu Rev Plant Biol. 2019;70:51-81. https://doi.org/10.1146/annurev-arplant-050718-100202.

8. Jarvis P, Dormann P, Peto CA, et al. Galactolipid deficiency and abnormal chloroplast development in the Arabidopsis MGD synthase 1 mutant. Proc Natl Acad Sci U S A. 2000;97(14):8175-8179. https://doi.org/10.1073/pnas.100132197.

9. Kobayashi K, Kondo M, Fukuda H, et al. Galactolipid synthesis in chloroplast inner envelope is essential for proper thylakoid biogenesis, photosynthesis, and embryogenesis. Proc Natl Acad Sci U S A. 2007;104(43):17216-17221. https://doi.org/10.1073/pnas.0704680104.

10. Liu B, Benning C. Lipid metabolism in microalgae distinguishes itself. Curr Opin Biotechnol. 2013;24(2):300-309. https://doi.org/10.1016/j.copbio.2012.08.008.

11. Moellering ER, Miller R, Benning C. Molecular Genetics of Lipid Metabolism in the Model Green Alga Chlamydomonas reinhardtii. Lipids in Photosynthesis. Springer Netherlands. 2009;139-155. https://doi.org/10.1007/978-90-481-2863-1_7.

12. Simionato D, Block MA, La Rocca N, et al. The response of Nannochloropsis gaditana to nitrogen starvation includes De Novo biosynthesis of triacylglycerols, a decrease of chloroplast galactolipids, and reorganization of the photosynthetic apparatus. Eukaryot Cell. 2013;12(5):665-676. https://doi.org/10.1128/EC.00363-12.

13. Wikfors GH, Ferris GE, Smith BC. The relationship between gross biochemical composition of cultured algal foods and growth of the hard clam, Mercenaria mercenaria (L.). Aquaculture. 1992;108(1):135-54. https://doi.org/10.1016/0044-8486(92)90324-E.

14. Pernet $F$, Tremblay R. Effect of varying levels of dietary essential fatty acid during early ontogeny of the sea scallop Placopecten magellanicus. Journal of Experimental Marine Biology and Ecology. 2004;310(1):73-86. https://doi.org/10.1016/j.jembe.2004.04.001.

15. Yang $\mathrm{M}$, Jiang JP, Xie $\mathrm{X}$, et al. Chloroplasts Isolation from Chlamydomonas reinhardtii under Nitrogen Stress. Front Plant Sci. 2017;8:1503. https://doi.org/10.3389/fpls.2017.01503.

16. Liu W, Pearce CM, Alabi AO, et al. Effects of microalgal diets on the growth and survival of larvae and post-larvae of the basket cockle, Clinocardium nuttallii. Aquaculture. 2009;293(3):248-254. https://doi.org/10.1016/j.aquaculture.2009.04.032.

17. Huang L, Xu J, Zong C, et al. Effect of high temperature on the lipid composition of Isochrysis galbana Parke in logarithmic phase. Aquaculture International. 2017;25(1):327-339. https://doi.org/10.1007/s10499-016-0031-z.

18. Su J, Ye M, Lou Y, et al. Low-molecular-mass organic acid and lipid responses of Isochrysis galbana Parke to high temperature stress during the entire growth stage. Algal Research. 2017;26:93-103. 
https://doi.org/10.1016/j.algal.2017.06.011.

19. Mourioux G, Douce R. Slow Passive Diffusion of Orthophosphate between Intact Isolated Chloroplasts and Suspending Medium. Plant Physiology. 1981;67(3):470-473. https://doi.org/10.1104/pp.67.3.470.

20. Alhattab M, Kermanshahi-Pour A, Brooks MS-L. Microalgae disruption techniques for product recovery: influence of cell wall composition. Journal of Applied Phycology. 2018;31(1):61-88. https://doi.org/10.1007/s10811-018-1560-9.

21. Fitzpatrick LM, Keegstra K. A method of isolating a high yield of Arabidopsis chloroplasts capable of efficient import of precursor proteins. Plant J. 2001;27(1):59-65. https://doi.org/10.1046/j.09607412.2001.01061.x.

22. Aronsson H, Jarvis P. A simple method for isolating import-competent Arabidopsis FEBS Lett. 2002;529(2-3):215-220. https://doi.org/10.1016/s0014-5793(02)03342-2.

23. Seigneurin-Berny D, Salvi D, Dorne AJ, et al. Percoll-purified and photosynthetically active chloroplasts from Arabidopsis thaliana Plant Physiol Biochem. 2008;46(11):951-955. https://doi.org/10.1016/j.plaphy.2008.06.009.

24. Piro A, Serra IA, Spadafora A, et al. Purification of intact chloroplasts from marine plant Posidonia oceanica suitable for organelle proteomics. Proteomics. 2015;15(23-24):4159-4174. https://doi.org/10.1002/pmic.201500246.

25. Mason CB, Bricker TM, Moroney JV. A rapid method for chloroplast isolation from the green alga Chlamydomonas reinhardtii. Nat Protoc. 2006;1(5):2227-2230. https://doi.org/10.1038/nprot.2006.348.

26. Hori T, Green JC. The ultrastructure of mitosis in Isochrysis galbana parke (Prymnesiophyceae). Protoplasma. 1985;125(1):140-151. https://doi.org/10.1007/BF01297359.

27. Arnon DI. Copper enzymes in isolated chloroplasts. Polyphenoloxidase in Beta vulgaris. Plant Physiology. 1949;24. https://doi.org/10.1104/pp.24.1.1.

28. Spurr AR. A low-viscosity epoxy resin embedding medium for electron microscopy. Journal of Ultrastructure Research. 1969;26(1):31-43. https://doi.org/10.1016/S0022-5320(69)90033-1.

29. Rausch T. The estimation of micro-algal protein content and its meaning to the evaluation of algal biomass I. Comparison of methods for extracting protein. Hydrobiologia. 1981;78(3):237-251. https://doi.org/10.1007/BF00008520.

30. Klein U, Chen C, Gibbs M, et al. Cellular Fractionation of Chlamydomonas reinhardii with Emphasis on the isolation of the chloroplast. Plant Physiology. 1983;72(2):481-487. https://doi.org/10.1104/pp.72.2.481.

31. Bligh EG, Dyer WJ. A rapid method of total lipid extraction and purification. Can J Biochem Physiol. 1959;37(8):911-7. https://doi.org/10.1139/059-099.

32. Xu J, Chen D, Yan X, et al. Global characterization of the photosynthetic glycerolipids from a marine diatom Stephanodiscus sp. by ultra performance liquid chromatography coupled with electrospray 
ionization-quadrupole-time of flight mass spectrometry. Anal Chim Acta. 2010;663(1):60-68. https://doi.org/10.1016/j.aca.2010.01.026.

33. Reyes CDL, Ortega MJ, Rodríguez-Luna A, et al. Molecular Characterization and Anti-inflammatory Activity of Galactosylglycerides and Galactosylceramides from the Microalga Isochrysis galbana. J Agric Food Chem. 2016;64(46):8783-8794. https://doi.org/:10.1021/acs.jafc.6b03931.

34. Roche SA, Leblond JD. Betaine lipids in chlorarachniophytes. Phycological Research. 2010;58(4):298-305. https://doi.org/:10.1111/j.1440-1835.2010.00590.x.

35. Li S, Xu J, Chen J, et al. Characterization of the triacylglycerol profile in marine diatoms by ultra performance liquid chromatography coupled with electrospray ionization-quadrupole time-of-flight mass spectrometry. Journal of Applied Phycology. 2014;26(3):1389-1398. https://doi.org/10.1007/s10811-013-0159-4.

36. Li S, Xu J, Chen J, et al. Structural elucidation of co-eluted triglycerides in the marine diatom model organism Thalassiosira pseudonana by ultra-performance liquid chromatography/quadrupole timeof-flight mass spectrometry. Rapid Commun Mass Spectrom. 2014;28(3):245-255. https://doi.org/10.1002/rcm.6784.

37. Yan X, Li H, Xu J, et al. Analysis of phospholipids in microalga Nitzschia closterium by UPLC-Q-TOFMS. Chinese Journal of Oceanology and Limnology. 2010;28(1):106-112. https://doi.org/10.1007/s00343-010-9263-3.

38. Huang Q, Lei H, Dong M, et al. Quantitative analysis of 10 classes of phospholipids by ultrahighperformance liquid chromatography tandem triple-quadrupole mass spectrometry. Analyst. 2019;144(13):3980-3987. https://doi.org/10.1039/c9an00676a.

39. Naumann I, Darsow KH, Walter C, et al. Identification of sulfoglycolipids from the alga Porphyridium purpureum by matrix-assisted laser desorption/ionisation quadrupole ion trap time-of-flight mass spectrometry. Rapid Commun Mass Spectrom. 2007;21(19):3185-3192. https://doi.org/10.1002/rcm.3190.

40. Li S, Xu J, Chen J, et al. The major lipid changes of some important diet microalgae during the entire growth phase. Aquaculture. 2014;428-429:104-110. https://doi.org/10.1016/j.aquaculture.2014.02.032.

41. Andreyev AY, Fahy E, Guan Z, et al. Subcellular organelle lipidomics in TLR-4-activated macrophages. J Lipid Res. 2010;51(9):2785-2797. https://doi.org/10.1194/jlr.M008748.

42. Sun J, Qiu C, Qian W, et al. Ammonium triggered the response mechanism of lysine crotonylome in tea plants. BMC Genomics. 2019;20(1):340. https://doi.org/10.1186/s12864-019-5716-z.

43. Yu FY, Liu BH, Chou HN, et al. Development of a sensitive ELISA for the determination of microcystins in algae. Journal of Agricultural \& Food Chemistry. 2002;50(15):4176-4182. https://doi.org/10.1021/jf0202483.

44. Mosmann T. Rapid colorimetric assay for cellular growth and survival: Application to proliferation and cytotoxicity assays. Journal of Immunological Methods. 1983;65(1):55-63. https://doi.org/10.1016/0022-1759(83)90303-4. 
45. Gnouma A, Sadovskaya I, Souissi A, et al. Changes in fatty acids profile, monosaccharide profile and protein content during batch growth of Isochrysis galbana (T.iso). Aquaculture Research. 2017;48(9):4982-4990. https://doi.org/10.1111/are.13316.

46. Gaude N, Brehelin C, Tischendorf G, et al. Nitrogen deficiency in Arabidopsis affects galactolipid composition and gene expression and results in accumulation of fatty acid phytyl esters. Plant $\mathrm{J}$. 2007;49(4):729-739. https://doi.org/10.1111/j.1365-313X.2006.02992.x.

47. Granafei S, Losito I, Palmisano F, et al. Unambiguous regiochemical assignment of sulfoquinovosyl mono- and diacylglycerols in parsley and spinach leaves by liquid chromatography/electrospray ionization sequential mass spectrometry assisted by regioselective enzymatic hydrolysis. Rapid Commun Mass Spectrom. 2017;31(18):1499-1509. https://doi.org/10.1002/rcm.7928.

48. Guschina IA, Harwood JL. Lipids and lipid metabolism in eukaryotic algae. Progress in Lipid Research. 2006;45(2):160-186. https://doi.org/10.1016/j.plipres.2006.01.001.

49. Yoshida H, Saiki M, Yoshida N, et al. Fatty acid distribution in triacylglycerols and phospholipids of broad beans (Vicia faba). Food Chemistry. 2009;112(4):924-928.

https://doi.org/10.1016/j.foodchem.2008.07.003.

50. Lim TK. Mimosa pudica. Edible Medicinal And Non-Medicinal Plants. Springer Netherlands. 2014;821-835. https://doi.org/10.1007/978-94-007-7395-0_66.

51. El Tahchy A, Petrie JR, Shrestha P, et al. Expression of Mouse MGAT in Arabidopsis Results in Increased Lipid Accumulation in Seeds. Front Plant Sci. 2015;6:1180. https://doi.org/10.3389/fpls.2015.01180.

52. Čopič A, Antoine-Bally S, Gimenez-Andres $M$, et al. A giant amphipathic helix from a perilipin that is adapted for coating lipid droplets. Nat Commun. 2018;9:1332. https://doi.org/10.1038/s41467-01803717-8.

53. Eltgroth ML, Watwood RL, Wolfe GV. Production and Cellular Localization of Neutral Long-Chain Lipids in the Haptophyte Algae Isochrysis Galbana and Emiliania Huxleyi Journal of Phycology. 2005;41(5):1000-1009. https://doi.org/10.1111/j.1529-8817.2005.00128.x.

54. Wilfling F, Wang H, Haas JT, et al. Triacylglycerol synthesis enzymes mediate lipid droplet growth by relocalizing from the ER to lipid droplets. Dev Cell. 2013;24(4):384-399. https://doi.org/10.1016/j.devcel.2013.01.013.

55. Browse J, Warwick N, Somerville CR, et al. Fluxes through the prokaryotic and eukaryotic pathways of lipid synthesis in the '16:3' plant, Arabidopsis thaliana. Biochem J. 1986;235(1):25-31. https://doi.org/10.1042/bj2350025.

56. Vothknecht UC, Soll J. Chloroplast membrane transport: interplay of prokaryotic and eukaryotic traits. Gene. 2005;354:99-109. https://doi.org/10.1016/j.gene.2005.04.021.

\section{Table}


Table 1 Comparison of enzyme activities in cell homogenate, crude, and purified chloroplasts from $I$. galbana Parke

\begin{tabular}{llll}
\hline Enzyme name & cell homogenate & crude chloroplasts & purified chloroplasts \\
\hline Rubisco & $11.85 \pm 0.8$ & $10.38 \pm 0.1$ & $11.09 \pm 0.6$ \\
COX & $0.24 \pm 0.0$ & $0.11 \pm 0.0$ & $0.06 \pm 0.0$ \\
PEPC & $9.64 \pm 0.4$ & $5.64 \pm 0.5$ & $2.72 \pm 0.2$ \\
\hline
\end{tabular}

Activity is expressed as U.per L of chlorophyll in three independent replicates. Cell homogenate was obtained by homogenization. Crude chloroplasts were obtained by differential centrifugation. Purified chloroplasts were obtained by differential centrifugation followed by purification using discontinuous density gradient centrifugation.

\section{Figures}




\section{sample}

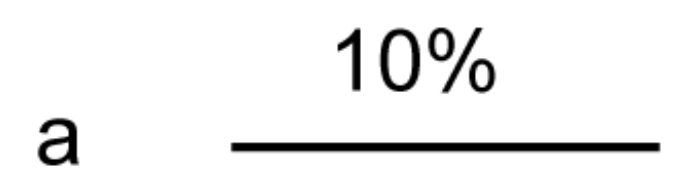

$30 \%$
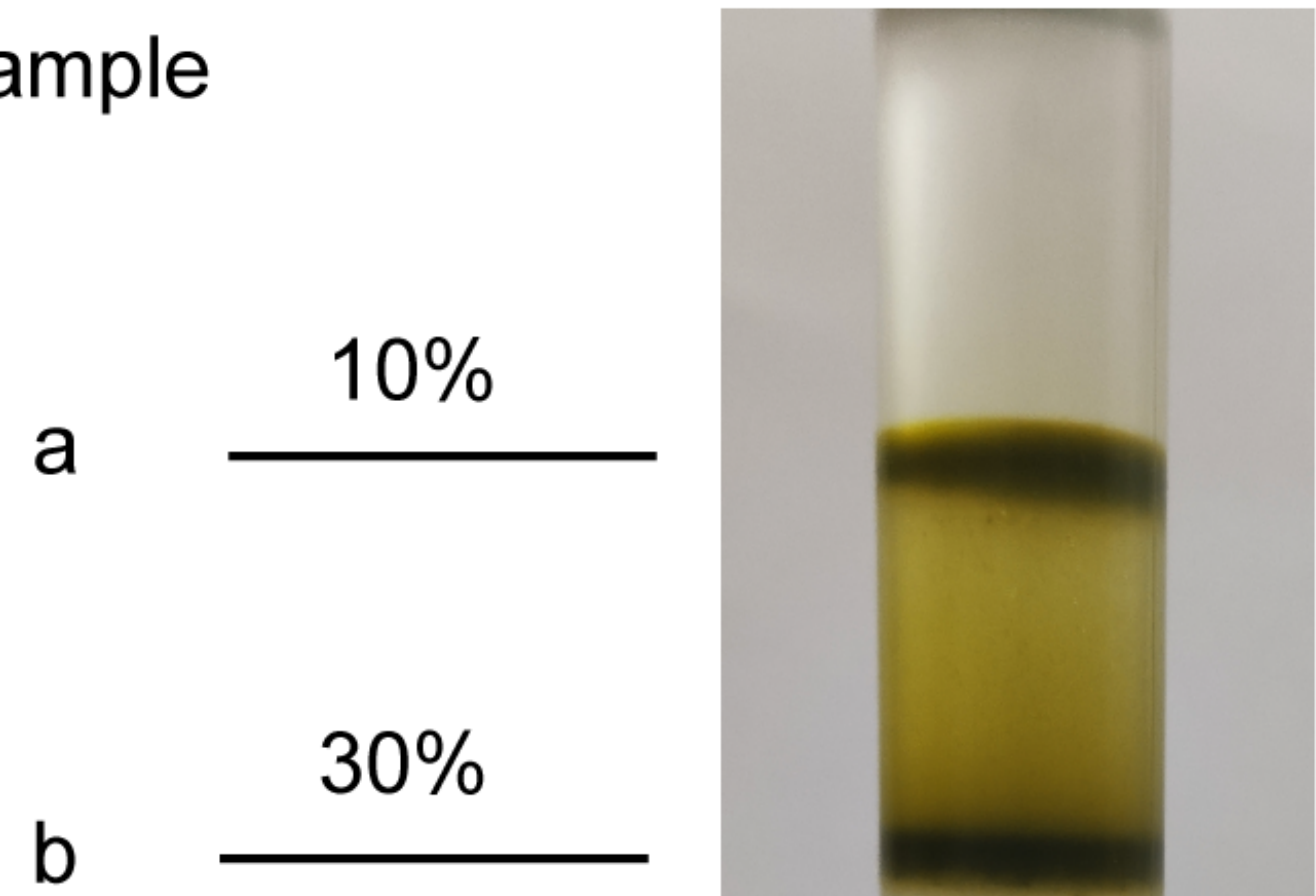

\section{$50 \%$}

C

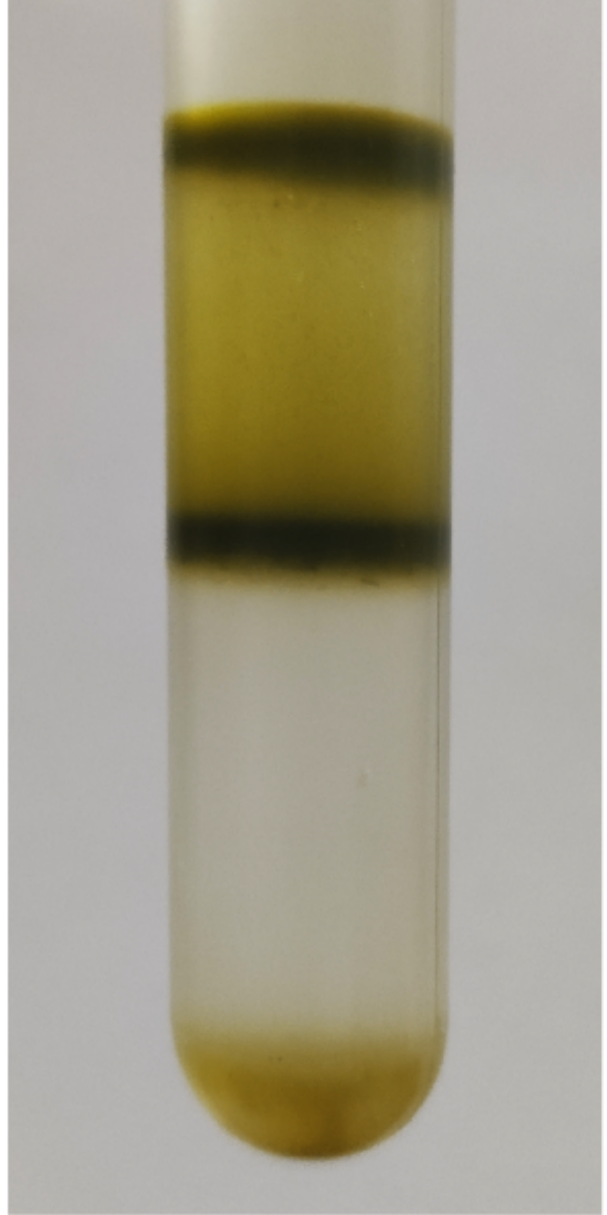

Figure 1

Typical Percoll gradient after centrifugation, and the percentages of Percoll in buffer for the various layers. a: broken chloroplasts, b: intact chloroplasts, c: intact cells. 

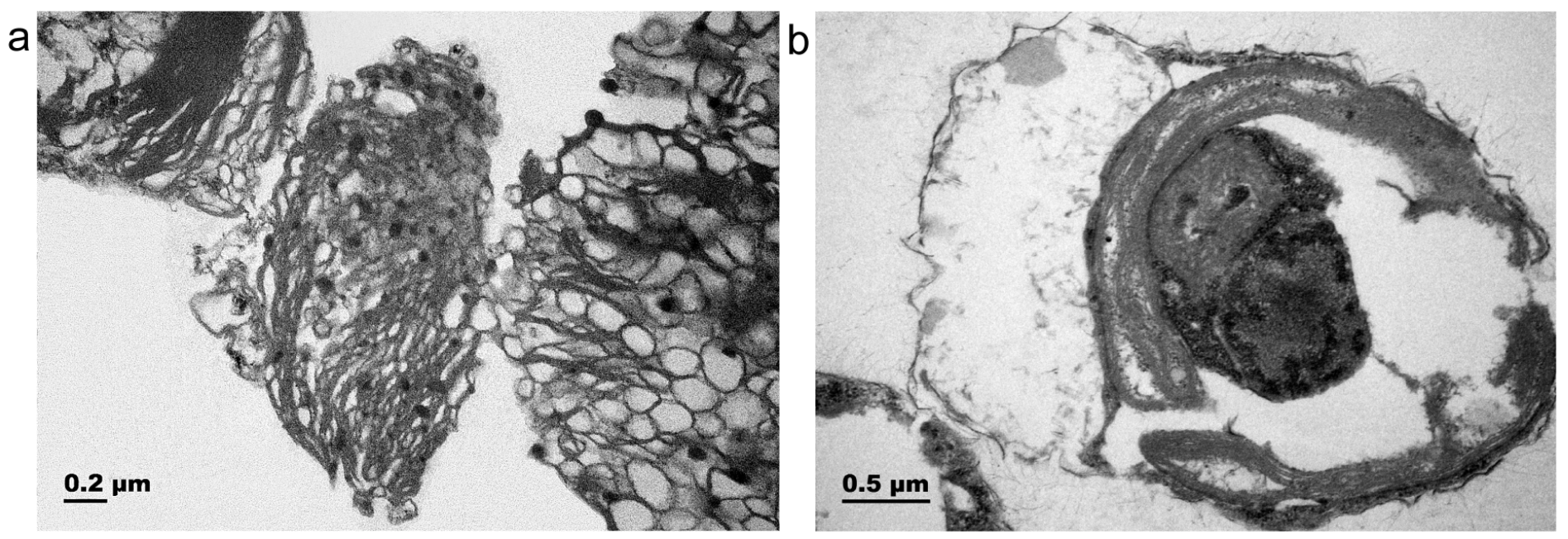

\section{Figure 2}

Microscopic images of the broken chloroplasts at 50,000x magnification (a) and the intact cell at $40,000 \times$ magnification (b). 

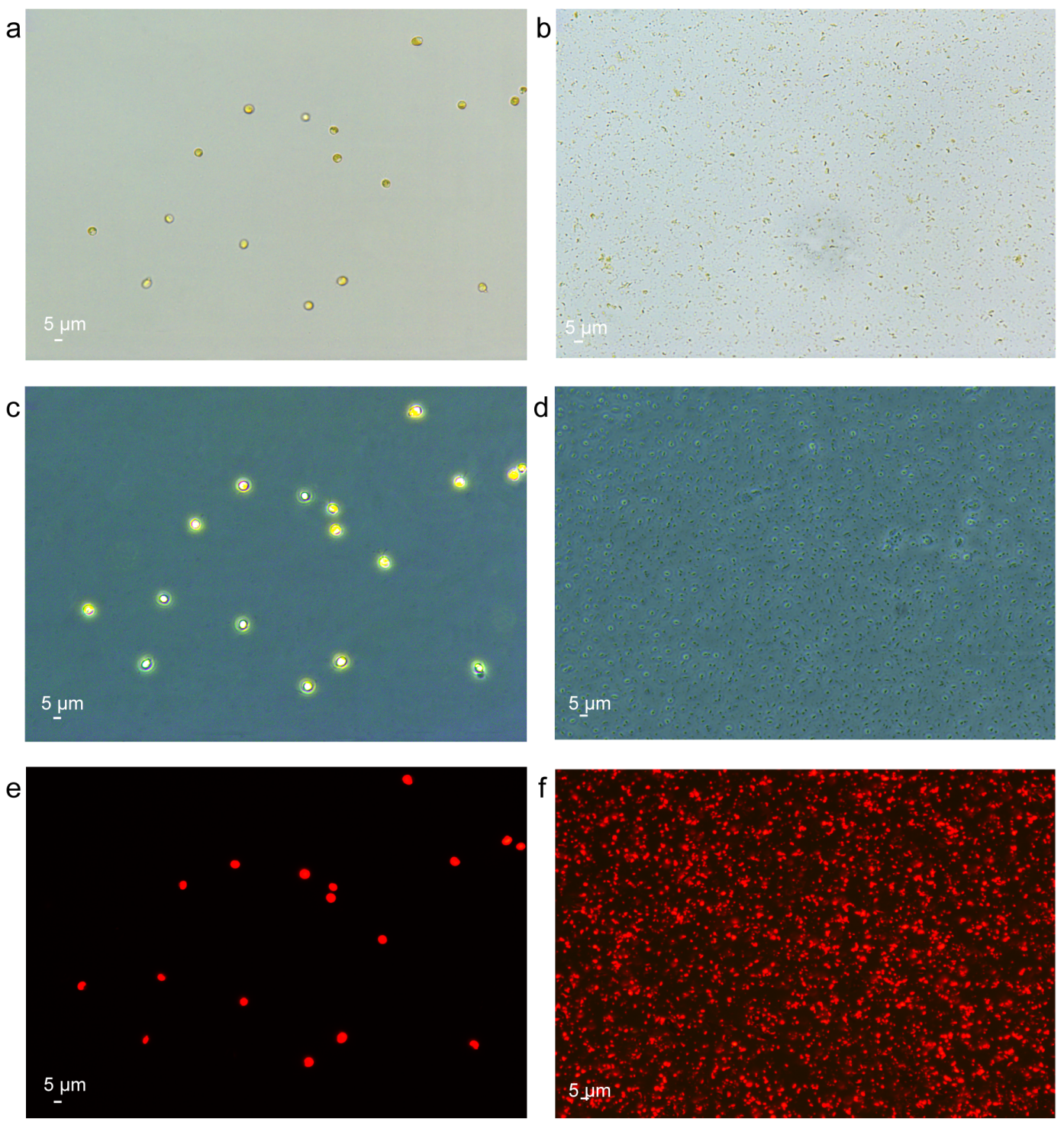

g

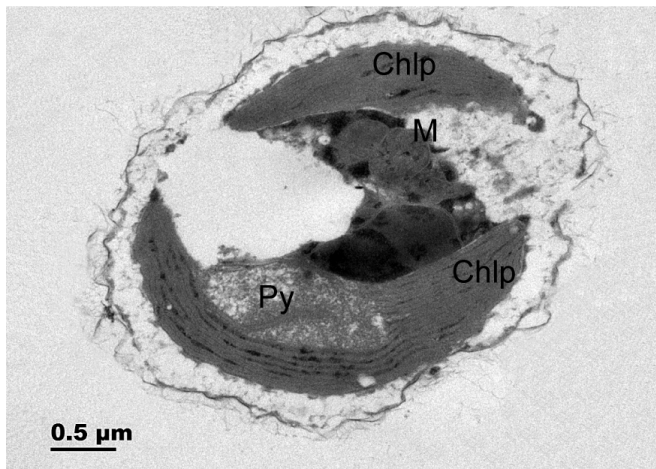

h

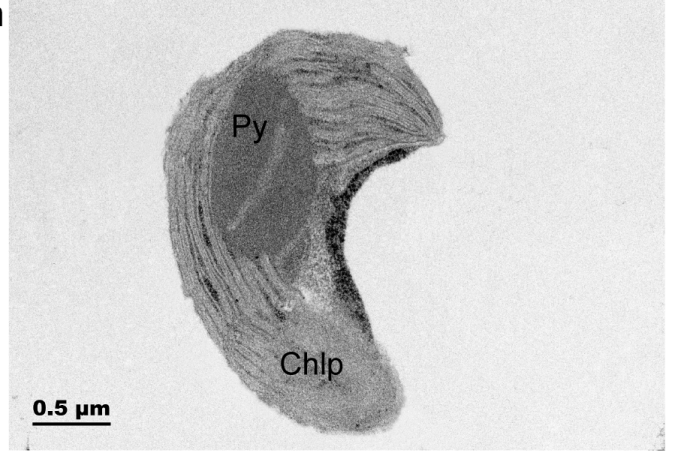

\section{Figure 3}

Micrographs of whole-cell and isolated chloroplasts from I. galbana Parke. a, c, e, g: Light and electron micrographs of I. galbana Parke. Light micrograph of I. galbana at 400x magnification (a), Phasecontrast micrograph of I. galbana at 400x magnification (c), Fluorescence micrograph of I. galbana at 400× magnification (e), and TEM image of I. galbana at 30,000 × magnification (g). b, d, f, h: Light and electron micrographs of purified chloroplasts. Chloroplasts purified from I. galbana Parke were analyzed 
by phase-contrast fluorescence microscopy at 400x magnification, light (b), phase contrast (d), and fluorescence (f), microscopy, and majority of the isolated chloroplasts were intact. The integrity of the chloroplasts was validated using TEM at 40,000x magnification (h). Chlp: chloroplasts; Py: pyrenoid.

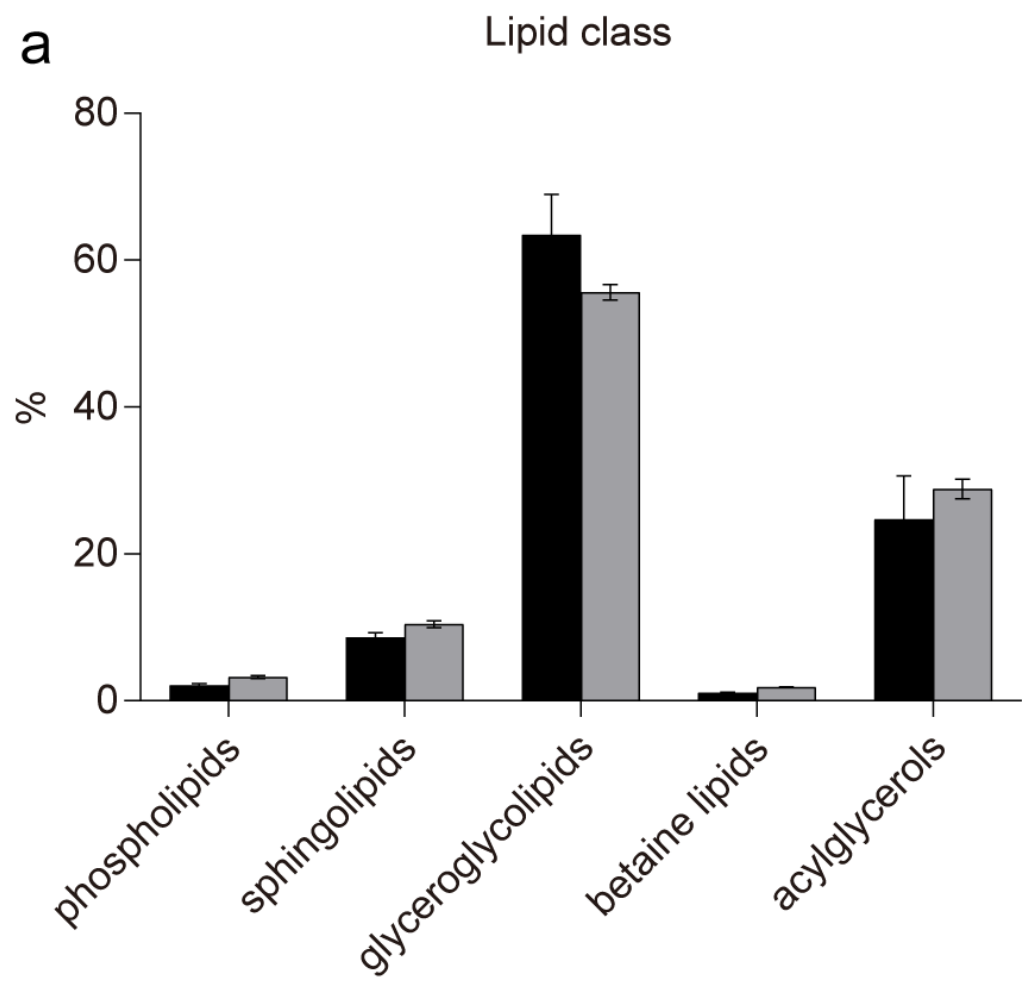

b

$$
\text { Lipid subclass }
$$

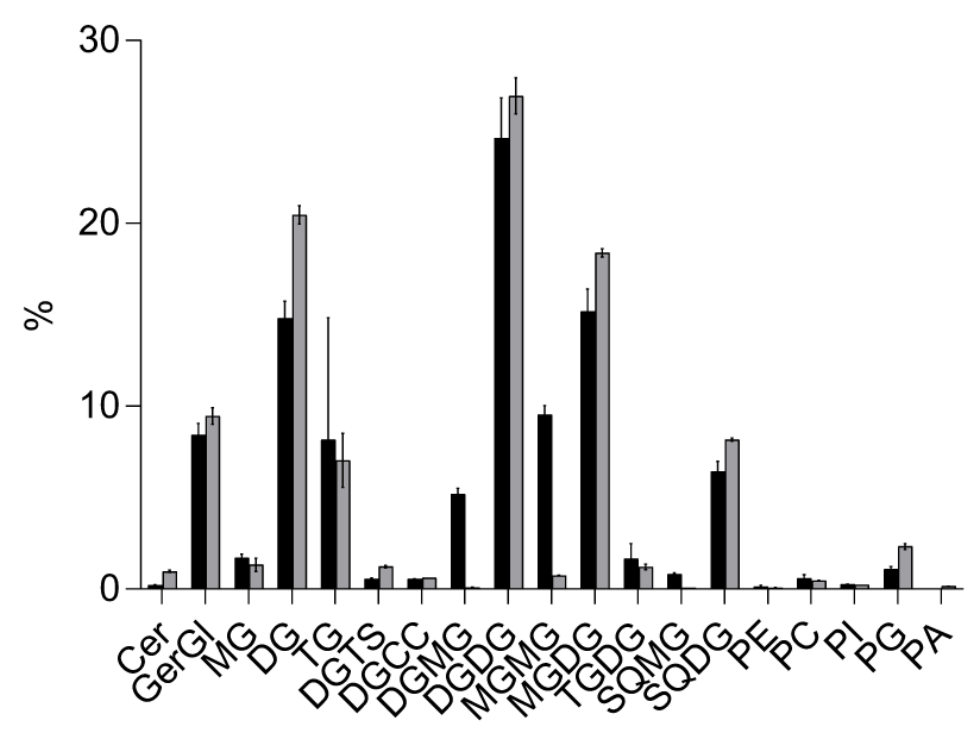

Figure 4

Total lipid composition of whole-cell (black bars) and chloroplast (gray bars) in I. galbana Parke. Lipid content is expressed as nmol lipid mg-1 of dry weight and then converted to the percentage of total lipid \pm 
standard error $(n=3)$.
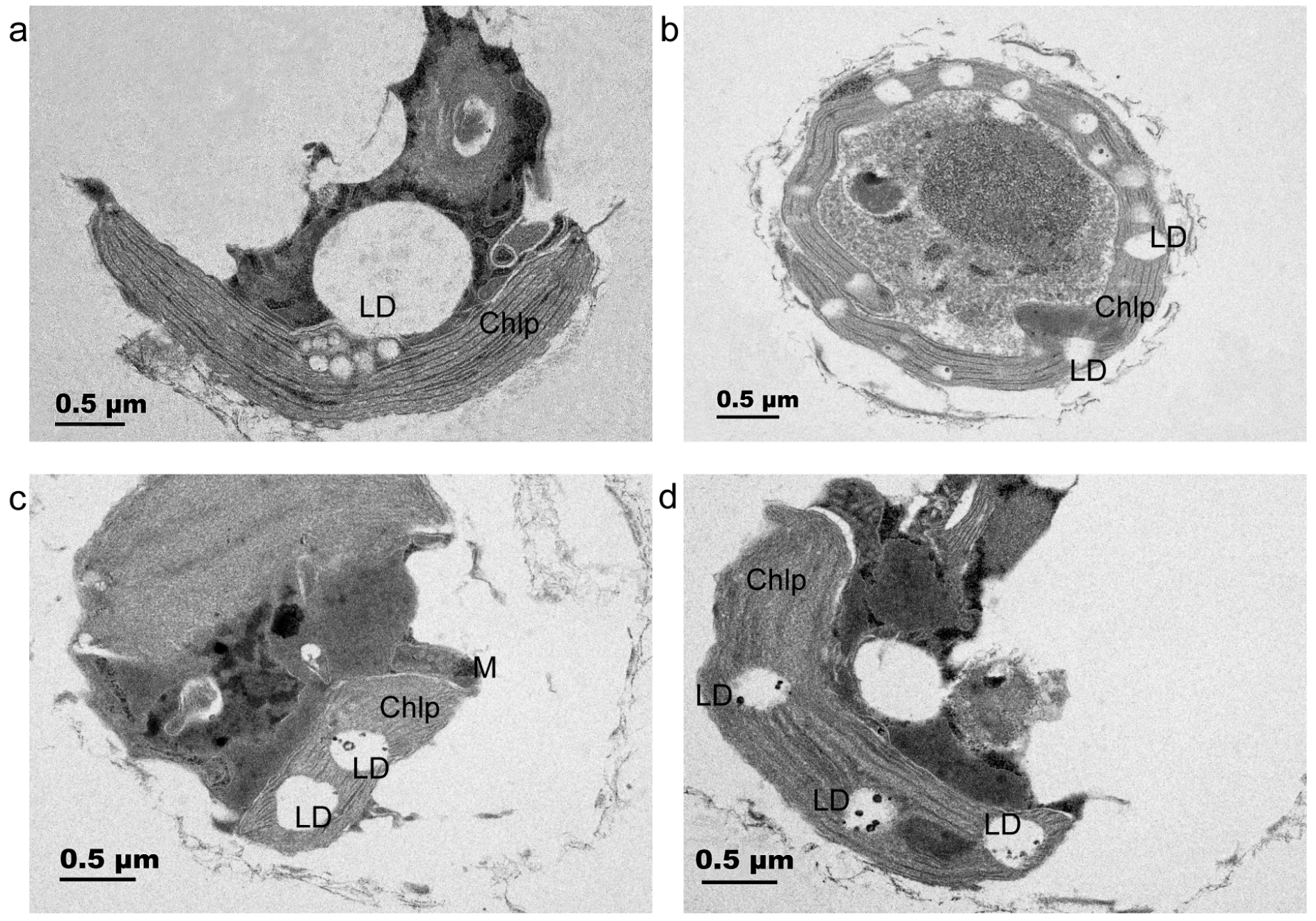

\section{Figure 5}

TEM micrographs of lipid droplets present in the chloroplast. Chlp: chloroplasts; LD: lipid droplet; M: mitochondrion. 
a

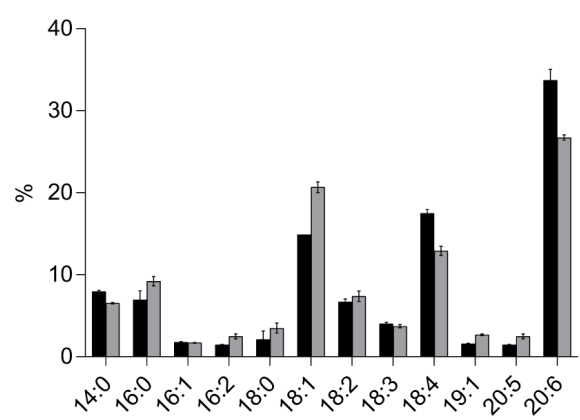

C

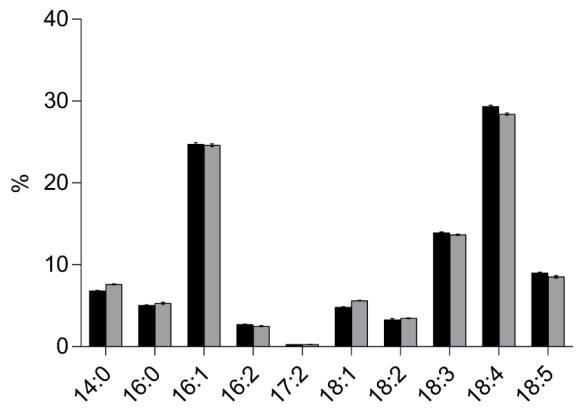

e

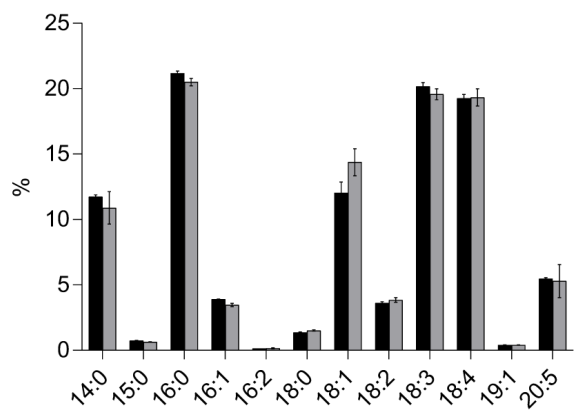

g

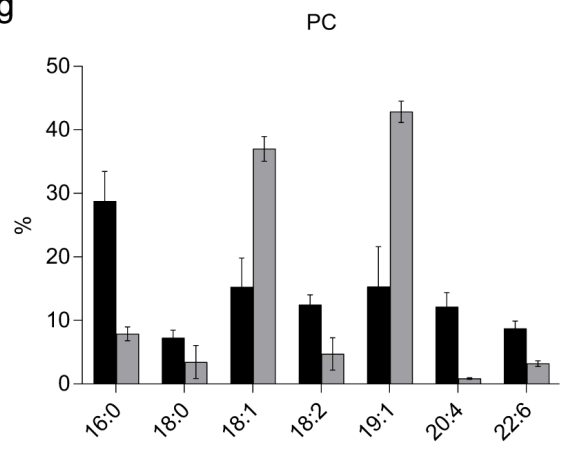

b

TG

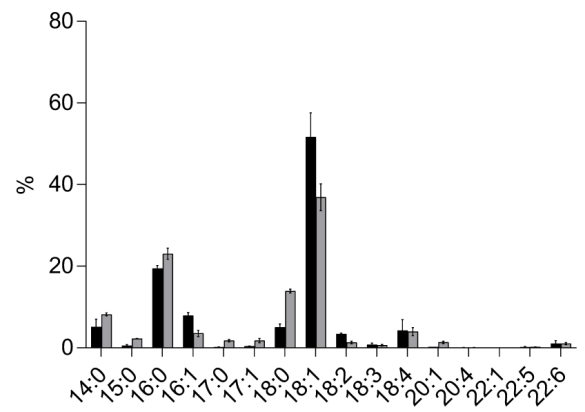

d

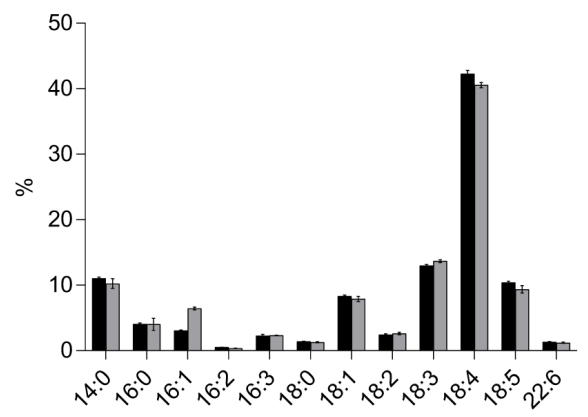

f

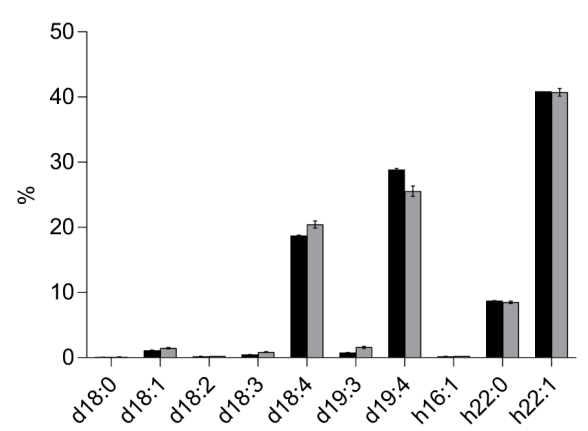

h

PG

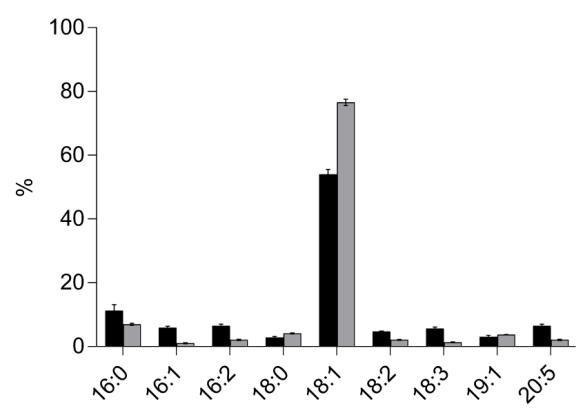

Figure 6

Fatty acid profiles of major lipid subclasses in the whole-cell and chloroplast of I. galbana Parke. Results are shown for some of the major lipid subclasses, DG (a), TG (b), DGDG (c), MGDG (d), SQDG (e), GerG1(f), PC (g), and PG (h), whole-cell (black bars) and chloroplasts (gray bars). Lipid content is expressed as nmol fatty acids mg-1 of dry weight and then converted to the percentage of total lipid \pm standard error $(n=3)$. 


\section{Supplementary Files}

This is a list of supplementary files associated with this preprint. Click to download.

- Additionalfile1TableS1.doc

- Additionalfile2Tables2.xlsx 